\title{
PICOCYANOBACTERIA FROM A CLADE OF MARINE Cyanobium REVEALED BIOACTIVE POTENTIAL AGAINST MICROALGAE, BACTERIA, AND MARINE INVERTEBRATES
}

\author{
Maria Sofia Costa1, Margarida Costa1, Vítor Ramos1,2, Pedro N. Leão1, Aldo Barreiro1, \\ Vítor Vasconcelos1,2, Rosário Martins1,3,4 \\ 1Interdisciplinary Centre of Marine and Environmental Research, Porto University, Porto, Portugal \\ 2Department of Biology, Faculty of Sciences, Porto University, Porto, Portugal \\ 3 Health and Environmental Research Center, Superior School of Allied Health Sciences of Porto, \\ Polytechnic Institute of Porto, Vila Nova de Gaia, Portugal \\ 4Institute for Molecular and Cell Biology, Porto University, Porto, Portugal
}

The production of bioactive compounds either toxic or with pharmacological applications by cyanobacteria is well established. However, picoplanktonic forms within this group of organisms have rarely been studied in this context. In this study, the toxicological potential of picocyanobacteria from a clade of marine Cyanobium strains isolated from the Portuguese coast was examined using different biological models. First, strains were identified by applying morphological and molecular approaches and cultured under lab conditions. A crude extract and three fractions reflecting a preliminary segregation of lipophilic metabolites were tested for toxicity with the marine microalga Nannochloropsis sp., the bacteria Pseudomonas sp., the brine shrimp Artemia salina, and fertilized eggs of the sea urchin Paracentrotus lividus.

No significant apparent adverse effects were noted against Artemia salina. However, significant adverse effects were found in all other assays, with an inhibition of Nannochloropsis sp. and Pseudomonas sp. growth and marked reduction in Paracentrotus lividus larvae length. The results obtained indicated that Cyanobium genus may serve as a potential source of interesting bioactive compounds and emphasize the importance of also studying smaller picoplanktonic fractions of marine cyanobacteria.

The photosynthetic prokaryotes cyanobacteria are important components and primary producers of marine, estuarine, and freshwater ecosystems. Among several characteristics that make this group of organisms attractive for scientific studies, the capability to produce unique secondary metabolites is one that is most explored (Nunnery et al., 2010; Tan,

2010). Among those metabolites, toxins were extensively explored due to the deleterious effects they induce on ecosystem equilibrium and human health (Codd et al., 2005; Zurawell et al., 2005; Martins and Vasconcelos, 2009).

Nevertheless, and owing to their ecological and biochemical diversity, cyanobacteria were found to be a prolific source of compounds with potential biotechnological applications, namely in the field of pharmacological agents. In fact, a wide range of secondary metabolites exhibiting pharmacodynamic properties such as antibacterial, antiviral, antifungal, and anticancer has been reported (Berry et al., 2008; Costa et al., 2014).

With respect to marine cyanobacteria, filamentous non-heterocystous genera such as Lyngbya, Moorea, Microcoleus, Schizothrix, Symploca, and Trichodesmium were considered for drug development and identified as promising taxa from which new biologically active compounds can be isolated (Tan, 2007; Engene et al., 2012). However, other picocyanobacteria genera such as Cyanobium, Prochlorococcus, Synechococcus, and Synechocystis have been overlooked, probably because these forms do not usually reach sufficiently high densities in environmental conditions and thus successful biomass production is limited to isolation and culturing.

These morphologically simple taxa are well known to occur in open ocean and coastal waters globally (Scanlan et al., 2009; Huang et al., 2012), some of which are major contributors to primary production (Waterbury et al., 1986; Chisholm et al., 1988; Liu et al., 1997).

However, taxonomic classification, and thus identification, is difficult to correctly establish as (1) there are few taxonomic characters present in these small coccoid cyanobacteria (Komarek et al., 1999), (2) there are morphological resemblances that exist between these and other taxa, and (3) there is a lack of experimental support derived from molecular-based approaches to identify picocyanobacteria. 
In fact, a number of lineages are recognized to exist among picocyanobacteria genera, which indicates that their taxonomy needs to be revised (Honda et al., 1999; Huang et al.,

2012). The biological activity displayed by marine and estuarine picocyanobacteria strains has been previously studied in our lab (Martins et al., 2007, 2008; Frazao et al., 2010;

Lopes et al., 2011; Costa et al., 2014) and by other investigators (Hamilton et al.,

2014). Since bioactivity effects were predominantly reported for strains of the Synechocystis and Synechococcus genera, the aim of this study was to assess the potential of novel marine Cyanobium strains as producers of bioactive compounds. To achieve this, five isolates were identified by a morphological and genomic approach, complemented with a phylogenetic analysis, and extensively cultured.

The bioactivity of the isolates, which are herein recognized to belong to the same phylotypes, was assessed by a battery of bioassays. Considering the ability of cyanobacteria to produce compounds toxic to coexisting organisms, assays with microalga Nannochloropsis sp., brine shrimp Artemia salina, and embryos of the sea urchin Paracentrotus lividus were performed. Bioassays with the bacteria Pseudomonas putida were also conducted in order to determine antibacterial potential.

\section{MATERIALS AND METHODS}

\section{Cyanobacteria Isolation, Characterization, and Culture}

Five marine cyanobacteria strains belonging to the genus Cyanobium were included in this study (Table 1). Strains were obtained from water samples and substrate collected on beaches from the Portuguese coast. For isolation purposes, raw biological materials were inoculated in liquid Z8 medium (Kotai, 1972) supplemented with $25 \mathrm{~g} / \mathrm{L} \mathrm{NaCl}$ and $10 \mu \mathrm{g} / \mathrm{ml}$ vitamin $\mathrm{B} 12$, for enrichment. When visible growth was detected in the media, aliquots were transferred and streaked onto solid Z8 medium plates containing $1.2 \%$ agar, and supplemented as already described. Single colonies were then selected and two subsamples were made: One was inspected under a microscope, while the other was aseptically streaked onto fresh Z8 medium agar plates.

This procedure was repeated until isolation was achieved and reconfirmed after transferring to liquid medium. The unicyanobacterial isolates obtained were kept in our collection (LEGE Culture Collection), at $19{ }^{\circ} \mathrm{C}$ and under a 12:12-h light (approximately $25 \mu \mathrm{mol} / \mathrm{m} 2 / \mathrm{s}$ photon irradiance): dark cycle, while isolation was carried out at $25^{\circ} \mathrm{C}$ under a 14:10-hr light (30-40 $\mu \mathrm{mol} / \mathrm{m} 2 / \mathrm{s}$ photon irradiance): dark cycle.

The morphology of the strains was examined using a BX41 light microscope coupled to a DP72 digital camera (Olympus, Hamburg, Germany), and morphometric measures were performed using image analysis software Cell B (Olympus). The identification of the cyanobacteria was performed according to the traditional classification system of Komárek and

TABLE 1. Strain Information for the Cyanobium sp. Isolates Included in This Study

\begin{tabular}{|c|c|c|c|c|c|c|}
\hline Strain & $\begin{array}{l}\text { Collection } \\
\text { date }\end{array}$ & $\begin{array}{l}\text { Sampling } \\
\text { site }^{a}\end{array}$ & $\begin{array}{l}\text { Latitude/longitude } \\
\text { coordinates }\end{array}$ & Isolation source & Morphometry $^{b}$ & $\begin{array}{l}\text { Accession } \\
\text { number }\end{array}$ \\
\hline LEGE 06098 & $16-07-2006$ & Martinhal & $\begin{array}{c}\mathrm{N} 37^{\circ} 01^{\prime} 07.30^{\prime \prime} / \mathrm{W} \\
8^{\circ} 55^{\prime} 36.17^{\prime \prime}\end{array}$ & $\begin{array}{l}\text { Green macroalgae, } \\
\text { intertidal zone }\end{array}$ & $1.0 \pm 0.2 \mu \mathrm{m}$ & KC469572 \\
\hline LEGE 06134 & $30-06-2006$ & Moledo & $\begin{array}{c}\mathrm{N} 41^{\circ} 50^{\prime} 58.68^{\prime \prime} / \mathrm{W} \\
8^{\circ} 52^{\prime} 0.18^{\prime \prime}\end{array}$ & $\begin{array}{l}\text { Sabellaria sp. reef, } \\
\text { intertidal zone }\end{array}$ & $0.8 \pm 0.1 \mu \mathrm{m}$ & KC469573 \\
\hline LEGE 06139 & 26-06-2006 & Aguda & $\begin{array}{c}\mathrm{N} 41^{\circ} 02^{\prime} 58.35^{\prime \prime} / \mathrm{W} \\
8^{\circ} 39^{\prime} 19.22^{\prime \prime}\end{array}$ & $\begin{array}{l}\text { Mytilus sp. shell, } \\
\text { intertidal zone }\end{array}$ & $0.8 \pm 0.1 \mu \mathrm{m}$ & KC469574 \\
\hline LEGE 07175 & 02-05-2007 & Martinhal & $\begin{array}{c}\mathrm{N} 37^{\circ} 01^{\prime} 07.30^{\prime \prime} / \mathrm{W} \\
8^{\circ} 55^{\prime} 36.17^{\prime \prime}\end{array}$ & Seawater, coastal & $1.0 \pm 0.2 \mu \mathrm{m}$ & KC469575 \\
\hline LEGE 07186 & 02-05-2007 & Martinhal & $\begin{array}{c}\mathrm{N} 37^{\circ} 01^{\prime} 07.30^{\prime \prime} / \mathrm{W} \\
8^{\circ} 55^{\prime} 36.17^{\prime \prime}\end{array}$ & $\begin{array}{l}\text { Submerged stone, } \\
\text { intertidal pool }\end{array}$ & $1.0 \pm 0.1 \mu \mathrm{m}$ & KC469576 \\
\hline
\end{tabular}

a Sites refer to Portuguese beaches.

${ }^{b}$ Mean $\pm \mathrm{SD}, n=20$. 
(Boone et al., 2001). Information for the strains used in this study is shown and summarized in Table 1. For biomass production, strains were grown in $\mathrm{Z8}$ medium supplemented with $\mathrm{NaCl}$ at a concentration of $20 \mathrm{~g} / \mathrm{L}$ (Martins et al. 2005). Cultures were maintained at $25{ }^{\circ} \mathrm{C}$, under a light:dark cycle of 14:10 h, provided by cool white fluorescent tubes. Cells were harvested after one month of growth by centrifugation, frozen, and freeze-dried.

\section{DNA Extraction, PCR, Cloning, and Sequencing}

Strains were characterized by molecular analysis of the 16S rRNA gene. Total genomic DNA was extracted from frozen samples using the Purelink Genomic DNA Mini Kit (Invitrogen, Carlsbad, CA) following the protocol described for gram-negative bacteria. The primers CYA359F and 1494R (Neilan et al., 1997) were used for amplifying and sequencing the 16S rRNA gene. The polymerase chain reaction (PCR) conditions were as follows: initial denaturation at $94 \cdot \mathrm{C}$ for 4 min, followed by 35 cycles of denaturation at $94 \cdot \mathrm{C}$ for $30 \mathrm{~s}$, annealing at $52 \cdot \mathrm{C}$ for $30 \mathrm{~s}$, and extension at $72 \cdot \mathrm{C}$ for $80 \mathrm{~s}$, and a final extension step at $72 \cdot \mathrm{C}$ for $5 \mathrm{~min}$. All PCR reactions were prepared in a volume of $20 \mu \mathrm{l}$ containing $1 \times$ PCR buffer, $2.5 \mathrm{mM} \mathrm{MgCl} 2,250 \mathrm{~m} M$ of each deoxynucleotide triphosphate, $10 \mathrm{pmol}$ of each of the primers, $0.5 \mathrm{U}$ of Taq DNA polymerase (Bioline, Luckenwalde, Germany) and $10 \mathrm{ng}$ of template DNA. PCR products were separated by electrophoresis on a 1.5\% (w:v) agarose gel. Gels were stained with ethidium bromide and photographed under ultraviolet (UV) transillumination.

Amplicons were purified using Cut\&Spin DNA Gel Extraction Columns (Grisp, Portugal), according to the manufacturer's instructions. Purified PCR products were then cloned into pGEM-T Easy vector (Promega, Madison, WI), and transformed into OneShot TOP10 chemically competent Escherichia coli cells (Invitrogen, Carlsbad, CA) using standard procedures following the manufacturer's instructions (Sambrook and Russell, 2001). Plasmid DNA was isolated using GenElute Plasmid Miniprep Kit (Sigma-Aldrich, St. Louis, MO) and sequenced (Macrogen, Inc., Seoul, Korea) using M13 primers. The sequences obtained in the present study were assessed for the existence of chimeras using the DECIPHER program (Wright et al., 2012) and deposited in GenBank under the accession numbers KC469572-KC469576 (see Table 1 for correspondence with strains).

\section{Phylogenetic Analysis}

The 16S rRNA gene sequences obtained were aligned with sequences from the best BLASTn hits in GenBank and with available sequences from picocyanobacterial reference strains according to Bergey's Manual of Systematic Bacteriology (Boone et al., 2001).

The multiple sequence alignment (using the clustal $\mathrm{W}$ algorithm) and phylogenetic analyses were performed using the MEGA 5 software package (Tamura et al., 2011). Following the

Bayesian Information Criterion (Tamura et al., 2011), the T92 + G + I model of nucleotide substitution was selected as the best-fitting model for the datasets. Phylogenetic trees were reconstructed using the maximum likelihood (ML) and maximum parsimony (MP) methods, and, as an indication of nodal support, bootstrap analyses were performed (1000 replicates for each method). Ambiguously aligned regions were omitted ("complete deletion" option) from the analyses. The topologies retrieved from the two methods were then evaluated using TreePuzzle 5.2 (Schmidt et al., 2002), and the best topology was selected according to the results of the test comparisons (one- and two-sided Kishino-Hasegawa test, Shimodaira-Hasegawa test, expected likelihood weights). The branch support values derived from the two analyses were then compared using TreeGraph 2 (Stover and Muller, 2010).

\section{Cyanobacteria Extracts}

Freeze-dried cyanobacterial biomass was extracted repeatedly, twice at room temperature and then at $40 \cdot \mathrm{C}$, with a methanol: dichloromethane (1:2) solution.

After extraction, the solvents were evaporated in vacuo. A portion of the resulting crude extract was fractionated by normal-phase column chromatography in disposable silica (2-g) cartridges 
(Phenomenex), using a solvent gradient of increasing polarity. Starting with $100 \%$ hexane, to $100 \%$ ethyl acetate, to $100 \%$ methanol, three fractions (A, B, and C) were obtained. The crude extract and respective fractions were then dissolved in dimethyl sulfoxide (DMSO) at different concentrations $(0.1,1$, and $10 \mathrm{mg} / \mathrm{ml})$.

\section{Bioassays}

Crude cyanobacterial extract and fractions were tested at final concentrations of 1,10 , and 100 $\mu \mathrm{g} / \mathrm{ml}$, using 96-well plates, except for the sea urchin assay, which was performed in 24- well plates and where concentrations were $0.1,1$, or $10 \mu \mathrm{g} / \mathrm{ml}$. All assays were run in triplicate and averaged.

\section{Nannochloropsis Growth Inhibition Assay}

The marine microalga Nannochloropsis sp. LEGE Z-004 was cultured under the same conditions as described for cyanobacterial biomass production. Microalgal cells were inoculated in $200 \mu \mathrm{l}$ test solution at a 0.1 optical density (OD) $(750 \mathrm{~nm})$. Potassium dichromate $(4 \mu \mathrm{g} / \mathrm{ml})$ was used as positive control. After $72 \mathrm{~h}$ of incubation, cell growth was estimated by measuring the OD at 750 nm in a microplate reader (Synergy HT, Biotek, Winooski, VT).

\section{Bacterial Growth Inhibition Assay}

The bacterial strain Pseudomonas putida NB3L (Lage and Bondoso, 2011) was grown in liquid M607 medium in the dark at $25^{\circ} \mathrm{C}$ with shaking, until the exponential growth phase was reached, and then was diluted to $0.1 \mathrm{OD}(750 \mathrm{~nm})$. A mixture of penicillin $(50 \mathrm{U} / \mathrm{ml})$, streptomycin $(50$ $\mu \mathrm{g} / \mathrm{ml})$, and neomycin $(100 \mu \mathrm{g} / \mathrm{ml})$ was used as positive control. OD at

$750 \mathrm{~nm}$ was measured after $24 \mathrm{~h}$ of incubation.

\section{Artemia salina acute toxicity assay}

Acute toxicity to the brine shrimp was screened using Artemia salina nauplii, freshly hatched (24 h) from dried cysts in artificial seawater. Aliquots $(10 \mu \mathrm{l})$ of nauplii solution containing about $15-$ 20 organisms were pipetted into microplate wells containing $200 \mu \mathrm{l}$ test solutions. Potassium dichromate was used as a positive control as described for the Nannochloropsis assay. Plates were incubated at $25^{\circ} \mathrm{C}$, in darkness. After 24 and $48 \mathrm{~h}$, the numbers of dead larvae and total numbers of shrimps per well were determined. Results were expressed as percent mortality.

\section{Paracentrotus lividus Embryo-Larval Acute Toxicity Assay}

Sea urchins were collected from rocky beach at Valadares (Porto, North Portugal, (N 41. 05_30.37_; W 8.39_28.40_). Bioassays were performed according to the methods described by Fernandez and Beiras (2001). Briefly, sea urchins were dissected and sperm and eggs pipetted from the gonads. A volume of $10 \mu \mathrm{l}$ undiluted sperm from one male was added to the egg suspension and carefully stirred to allow fertilization. Twenty fertilized eggs $/ \mathrm{ml}$ were exposed to $3000 \mu \mathrm{l}$ test solutions prepared in artificial seawater. After $48 \mathrm{~h}$ of incubation at $20 \cdot \mathrm{C}$ in the dark, solutions were fixed in 36-38\% formaldehyde. Embryogenesis success was evaluated by formation of plutei larvae and larvae length.

\section{Statistical Analysis}

Data were analyzed using general linear models or generalized linear models. The dependent variables were those used to estimate growth (percent viability, OD, larva size).

Treatment, time, and cyanobacterial strain were used as fixed factor. For the analysis of sea urchin assay, a mixed-effects model was employed with nested block design. Normality was tested in the model residuals with the Shapiro-Wilks test. Nonnormal data were transformed using the 
Box-Cox function. Then, if the normality test was still negative, a generalized linear model with gamma distribution was employed. In these cases, fit to gamma distribution was tested as the dependent variable (sometimes also transformed with the Box-Cox function). In some of the analyses, clear outliers were omitted from the data set. Post hoc pairwise comparisons were performed with the Tukey's or Dunnett's test. Whenever usingTukey's test, homogeneous subsets of treatment levels were obtained based on significance levels.

Those levels that did not differ significantly among them were classified into the same subset. Homogeneous subsets were not calculated for those factors with low number of levels or few significantly different pairwise comparisons. The criterion for significance was set at $p<.05$. As a measure of standardized effect size, the value of Dunnett's $t$ statistic was calculated for each treatment level, averaged over comparisons against all other levels. The software employed was $\mathrm{R}$ version 2.15.2 with functions from base, stats, car, multcomp, and nlme packages.

\section{RESULTS}

\section{Identification and Phylogeny of the Isolates}

The morphological characterization of the picocyanobacterial isolates showed that cells were mainly spherical with some also being shortly rod-shaped (Figure S1; see Supplementary Material). Following botanical taxonomy (Komárek and Anagnostidis, 1998; Komarek et al., 1999), morphological and ecological features of the organisms enabled us to identify the strains as Cyanobium sp. This identificationis also in accordance with the criteria of Bergey's classification (Boone et al., 2001). Taking into account the 16S rRNA gene sequences, the best BLASTn match for all strains was Cyanobium sp. NS01 (99\% similarity). This strain was previously isolated from central North Sea waters (Fuller et al., 2003).

Regarding their phylogenetic placement among the picocyanobacterial diversity, data demonstrated (Figure 1) that the strains were placedtogether in a major clade that comprised two well-defined subclades: the first containing Synechococcus spp. along with a reference strain (WH 8103, cluster 5.1), and the second, Prochlorococcus marinus strains. In addition, two small subclades emerged, supported byboth ML and MP methodologies; one of the subclades included other Cyanobium sp. strainsfrom our culture collection, and the other comprised three freshwater isolates, including the reference strain PCC 6307 (cluster 1), which is also the holotype for the genus Cyanobium (Rippka and Cohen-Bazire, 1983). The other sequences from this large clade belong to strains indistinctly assigned to Synechococcus and Cyanobium (some of which are reference strains). 


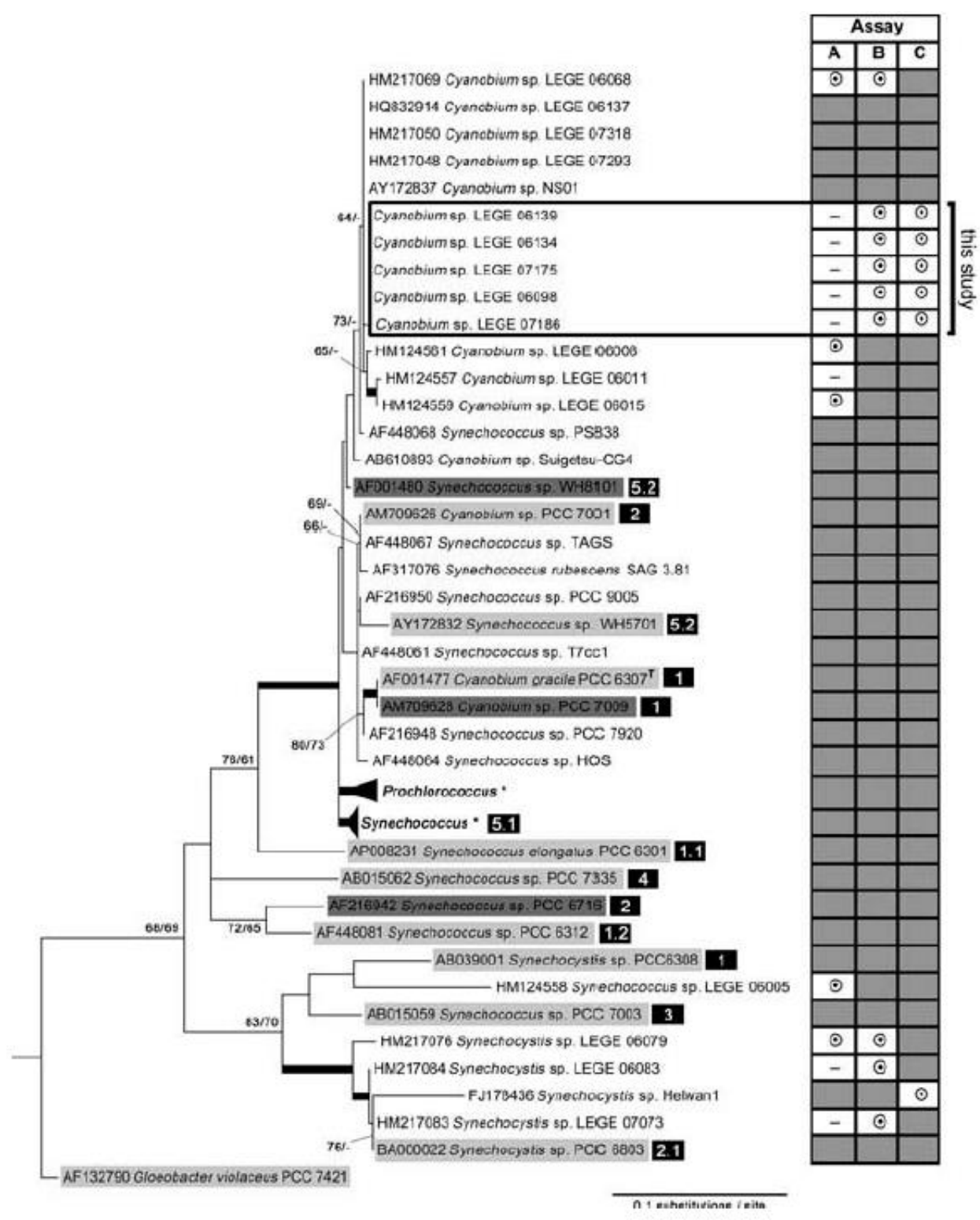

FIGURE 1. Maximum likelihood tree of picocyanobacterial 16S rRNA gene sequences (638 positions) and bioassay results from tested strains in this and other studies studies (A, Artemia salina; B, Pseudomonas sp.; C, Paracentrotus lividus). The nodal support values indicated near internal branches were determined by ML and MP methods, respectively; bootstrap values below $60 \%$ were omitted. Thick tree branches indicate $\geq 80 \%$ bootstrap values support. Reference strains are highlighted in light gray and their close relatives in dark gray, while the holotype species for the genus Cyanobium is marked with $\left({ }^{\top}\right)$. Numbered boxes refer to reference strains' clusters according to Boone et al., 2001. The condensed "Synechococcus clade" contains the reference strain WH 8103 (accession number: AF311293), while the "Prochlorococcus clade" encloses CCMP1375 (AE017126). The tree was rooted using Chloroflexus aurantiacus J-10-fl (CP000909) as outgroup, and removed for clarity.

\section{Bioactivity of Isolates}

For the assay with Nannochloropsis, a generalized linear model was fitted with treatment (crude extract and fractions) and cyanobacterial strains as fixed factors. The analysis of deviance found all factors significant (treatment, time and strain) (Figure 2). The homogeneous subsets for "treatment" showed level Fraction B at $1 \mu \mathrm{g} / \mathrm{ml}$ as the lower viability group. For "strain," no significant differences were found (Figure 2).

In the bacteria assay, a general linear model was fitted with the same formulation as for Nannochloropsis. An analysis of variance found all factors significant. A post hoc analysis was performed with Dunnett's test (reference level: 

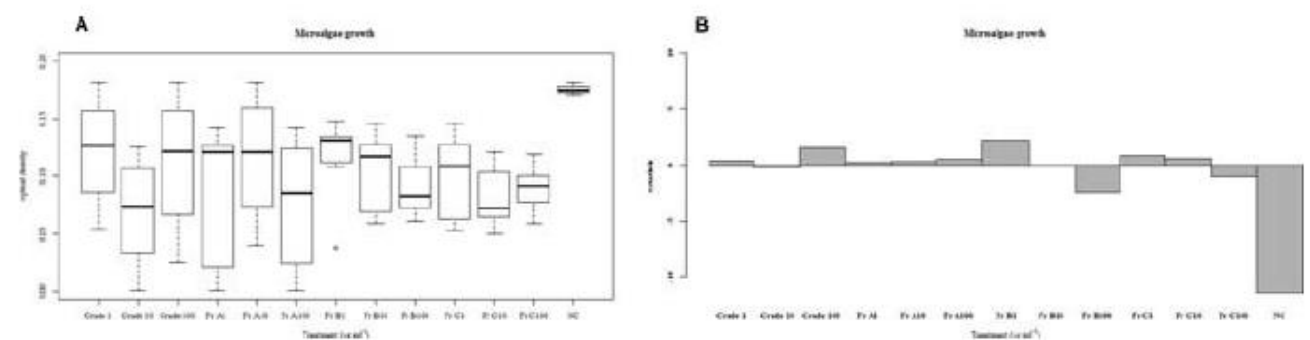

FIGURE 2. Effects of cyanobacterial extracts on Nannochloropsis growth. (A) Microalgae growth rate per treatment (cyanobacterial extracts). (B) Averaged Dunnett $t$ statistic for the same variable (see Methods section).

negative control). This test demonstrated significant differences with the following levels: Crude $1 \mu \mathrm{g} / \mathrm{ml}$, Crude $10 \mu \mathrm{g} / \mathrm{ml}$, Fr C $1 \mu \mathrm{g} / \mathrm{ml}$, and Fr C $10 \mu \mathrm{g} / \mathrm{ml}$. For "strain," no significant differences were found.

In the Artemia salina acute toxicological assay, no significant percent mortality was detected and thus no bioactivity was considered expressed (data not shown).

In the $P$. lividus bioassay, a general mixedeffects linear model was fitted using treatments and cyanobacterial strains as fixed factors.

Block (location of replicate groups in the chamber) was used as a random factor. An analysis of variance of this model found all factors significant, treatment and strain (Figure 3). A post hoc Dunnett's test (reference level: negative control) showed significant difference with level Fr B $10 \mu \mathrm{g} / \mathrm{ml}$. For "strain" no significant differences were found.

\section{Bioactivity Pattern Among Phylotypes}

To better visualize the bioactivity of extracts from diverse picocyanobacteria, a summary next to the phylogenetic tree is provided (Figure 1), with bioassay results obtained in this study compared to those from previous studies (Frazao et al., 2010; Semary and Naby,

2010; Lopes et al., 2011).The same bioactivity pattern was observed for isolates used in our study. Nevertheless, unlike that observed for other LEGE strains that represent closely related phylotypes, no apparent bioactivity was detected for the A. salina assay. Among these, only the previously studied Cyanobium sp. LEGE 06011 (Frazao et al., 2010) was also not active for this particular assay.

\section{DISCUSSION}

The morphological identification attempted here could not be carried out more stringently since the attributes of the strains were not assignable to any species with validly published names (Komárek and Anagnostidis, 1998). Thus, the strains were only identified at the genus level. The picocyanobacteria are recognized as having few characters, and as a result, their classification based on cytomorphological features is difficult (Komarek et al., 1999). Similarly, the 16S rRNA gene sequencing did not enable us to reach a
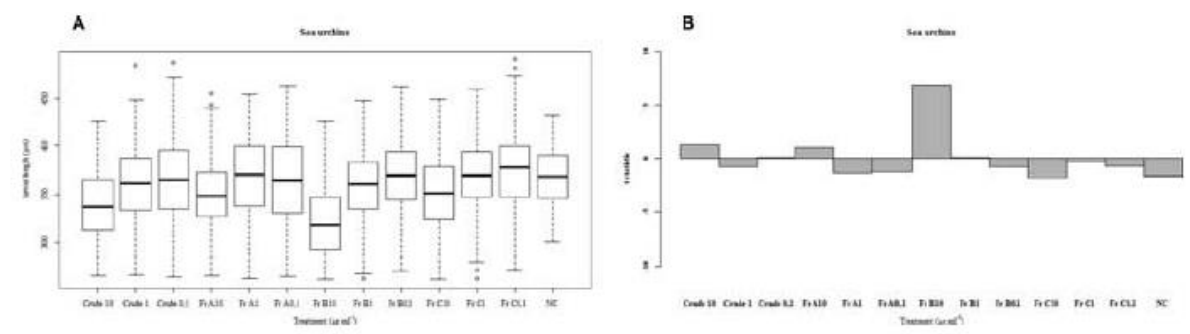

FIGURE 3. Effects of cyanobacterial extracts on Paracentrotus lividus larvae length. (A) Embryonic size per treatment (cyanobacterial extracts). (B) Averaged Dunnett $t$ statistic for the same variable (see Methods section). 
higher taxonomic resolution. The best hits retrieved from GenBank were sequences from Cyanobium spp. and Synechococcus spp. that, along with the sequences from our strains, resulted in closely related phylotypes (Figure 1).

This seemingly incongruent phylogeny is actually the well-recognized polyphyly of some morphotypes that are presumed to belong to the same cyanobacterial taxon, which is specifically true for several picocyanobacterial taxa (Honda et al., 1999; Robertson et al., 2001). Consequently, if a comparison of the presence or absence of particular aspects (e.g., bioactivity potential of extracts) in different morphologically identified taxa is to be made, this unresolved taxonomy might yield misleading conclusions. For this reason, it is preferred to compare phylotypes. Hence, in this investigation, marine Cyanobium strains shown to belong to the same subclade (Figure 1) were used, and their potential as producers of bioactive compounds was tested. The results obtained demonstrated that these Cyanobium strains, in general, inhibited microalgae and bacterial growth and induced a decrease in P. lividus larvae. When comparing these data with available results from less related phylotypes (Martins et al., 2005, 2007; Frazao et al., 2010) (Figure 1), it becomes evident that the limited number of picocyanobacteria studied to date exhibited activity in the majority of assays in which extracts were tested. The exceptions were two Synechocystis sp. strains (LEGE 06083 and LEGE 07073), which did not demonstrate toxicity for A. salina assay. Prior to this study, activity toward members of the Pseudomonas genus was tested only once for a picocyanobacterium with available 16S rRNA gene sequence. The strain in question is Synechocystis sp. Helwan1 and its lipophilic extract also inhibited growth of this bacterium (Semary and Naby, 2010). The outcome noted from Figure 1 is somewhat biased, since the results presented are just for picocyanobacteria with available 16S rRNA gene sequences. There are other studies on the bioactivity of extracts from picocyanobacteria (Martins et al., 2007, 2008), but the isolates used therein were not characterized by molecular markers (particularly, the 16S rRNA gene sequence). Thus, even if they are assigned to the same taxa as those present on the phylogenetic tree, their placement remains uncertain. Therefore, it should be noted that some of the picocyanobacterial diversity known to show bioactivity is not covered in this presented phylogenetic tree.

With a crude extract and three fractions of different polarity, a preliminary segregation of the lipophilic metabolites in the cells was achieved. Among crude extract and fractions, in general, fraction $\mathrm{B}$ was found to be the one with a most pronounced adverse effect.

Fraction B corresponds to the extraction eluted from the silica column with a higher proportion of ethyl acetate corresponding to compounds with an intermediate polarity, which are known to include cyclic lipopeptides or depsipeptides (Luesch et al., 2002; Han et al., 2006).

The diversity of marine cyanobacteria bioactive compounds already identified belongs to such chemical classes of compounds. To cite only a few, the cyclic depsipeptides aurilides, isolated from Lyngbya majuscule probably Moorea producens (Engene et al., 2012), were shown to be inhibitors of different cancer cell lines (Han et al., 2006) and the cyclic hexapeptides venturamides A and B, isolated from a marine Oscillatoria sp., displayed antimalarial activity (Linington et al., 2007). Interestingly, evidence indicated that the crude extract did not produce similar inhibitory effects as faction B. This may be attributed to concentration of the toxic compound. Although the tested concentrations were the same, the compound inducing the effect is, in principle, more concentrated in fraction B than in crude extract. Alternatively, in the crude extract, an interaction of the toxic compound with others may have altered toxicity, consequently resulting in differences between crude extracts and fractions B.

Our results, along with the findings from previous studies, emphasize the importance to also explore smaller forms of cyanobacteria for bioactive and toxicological purposes. The genus Cyanobium then presents itself as a source of bioactive compounds with effects on other organisms, namely coexisting organisms. Since this bioactivity is reflected in terms of toxicity, the occurrence of these picocyanobacteria might thus be seen as a threat to ecosystem equilibrium. Inhibition of bacterial growth is, however, a promising result with respect to the pharmacological and biotechnological applications of compounds. 
Identifying new sources of bioactive compounds represents the initial step in the process of discovering natural drugs. In this sense, this study represents a contribution to broaden the range of cyanobacteria from which new compounds with relevant bioactivity profiles might be isolated. According to our results, fraction B is promising for the isolation of compounds in the studied strains. Future investigations need to focus on the isolation and identification of compounds, as well as on the evaluation of their bioactive profile.

\section{REFERENCES}

Berry, J. P., Gantar, M., Perez, M. H., Berry, G., and Noriega, F. G. 2008. Cyanobacterial toxins as allelochemicals with potential applications as algaecides, herbicides and insecticides. Mar. Drugs 6: 117-146.

Boone, D. R., Castenholz, R. W., and Garrity, G. M. 2001. The Archaea and the Deeply Branching and Phototrophic Bacteria. In Bergey's manual of systematic bacteriology, 473-553. New York: Springer.

Chisholm, S. W., Olson, R. J., Zettler, E. R., Goericke, R., Waterbury, J. B., and Welschmeyer, N. A. 1988. A novel free-living prochlorophyte abundant in the oceanic euphotic zone. Nature 334: 340-343.

Codd, G. A., Morrison, L. F., and Metcalf, J. S. 2005. Cyanobacterial toxins: Risk management for health protection. Toxicol. Appl. Pharmacol. 203: 264-272.

Costa, M., Garcia, M., Costa-Rodrigues, J., Costa, M. S., Ribeiro, M. J., Fernandes, M. H., Barros, P., Barreiro, A., Vasconcelos, V., and Martins, R. 2014. Exploring bioactive properties of marine cyanobacteria isolated from the Portuguese coast: High potential as a source of anticancer compounds. Mar. Drugs 12: 98-114.

Engene, N., Rottacker, E. C., Kastovsky, J., Byrum, T., Choi, H., Ellisman, M. H., Komárek, J., and Gerwick, W. H. 2012. Moorea producens gen. nov., sp. nov. and Moorea bouillonii comb. nov., tropical marine cyanobacteria rich in bioactive secondary metabolites. Int. J. Syst. Evol. Microbiol. 62:1171-1178.

Fernández, N., and Beiras, R. 2001. Combined toxicity of dissolved mercury with copper, lead and cadmium on embryogenesis and early larval growth of the Paracentrotus lividus sea urchin. Ecotoxicology 10: 263-334.

Frazao, B., Martins, R., and Vasconcelos, V. 2010. Are known cyanotoxins involved in the toxicity of picoplanktonic and filamentous North Atlantic marine cyanobacteria? Mar. Drugs 8: 1908-1919.

Fuller, N. J., Marie, D., Partensky, F., Vaulot, D., Post, A. F., and Scanlan, D. J. 2003. Cladespecific 16s ribosomal DNA oligonucleotides reveal the predominance of a single marine Synechococcus clade throughout a stratified water column in the Red Sea. Appl. Environ. Microbiol. 69: 2430-2443.

Hamilton, T. J., Paz-Yepes, J., Morrison, R. A., Palenik, B., and Tresguerres, M. 2014. Exposure to bloom-like concentrations of two marine Synechococcus cyanobacteria (Strains Cc9311 and Cc9902) differentially alters fish behaviour. Conserv. Physiol. 2: 1-9.

Han, B., Gross, H., Goeger, D. E., Mooberry, S. L., and Gerwick, W. H. 2006. Aurilides B and $\mathrm{C}$, cancer cell toxins from a Papua New Guinea collection of the marine cyanobacterium Lyngbya majuscula. J. Nat. Prod. 69: 572-575. 
Honda, D., Yokota, A., and Sugiyama, J. 1999. Detection of seven major evolutionary lineages in cyanobacteria based on the 16s rRNA gene sequence analysis with new sequences of five marine Synechococcus strains. J. Mol. Evol. 48: 723-739.

Huang, S., Wilhelm, S. W., Harvey, H. R., Taylor, K., Jiao, N., and Chen, F. 2012. Novel lineages of Prochlorococcus and Synechococcus in the global oceans. ISME J. 6: 285-297.

Komárek, J., and Anagnostidis, K. 1998. Cyanoprokaryota 1. Teil: Chroococcales. In Süsswasserflora Von Mitteleuropa, ed. H. Ettl, G. Gärtner, H. Heynig, and D. Mollenhauer, vol. 19(1), 548. Stuttgart, Germany: Gustav Fischer.

Komárek, J., Kopecky, J., and Cepak, V. 1999. Generic characters of the simplest cyanoprokaryotes cyanobium, cyanobacterium and Synechococcus. Cryptogamie Algol. 20: 209222.

Kotai, J. 1972. Instructions for preparation of modified nutrient solution Z8 for algae, Norwegian. Publication B-11769. Oslo, Norway: Institute for Water Research.

Lage, O. M., and Bondoso, J. 2011. Planctomycetes diversity associated with macroalgae. FEMS Microbiol. Ecol. 78: 366-375.

Linington, R. G., Gonzalez, J., Urena, L. D., Romero, L. I., Barria, E. O., and Gerwick, W. H. 2007. Venturamides A and B: Antimalarial constituents of the Panamanian marine Cyanobacterium oscillatoria sp. J. Nat. Prod. 70: 397-401.

Liu, H. B., Nolla, H. A., and Campbell, L. 1997. Prochlorococcus growth rate and contribution to primary production in the equatorial and subtropical North Pacific Ocean. Aquat. Microb. Ecol. 12: $39-47$.

Lopes, V. R., Schmidtke, M., Fernandes, M. H., Martins, R., and Vasconcelos, V. 2011. Cytotoxicity in L929 fibroblasts and inhibition of Herpes simplex virus Type 1 kupka by estuarine cyanobacteria extracts. Toxicol. In Vitro 25: 944-950.

Luesch, H.,Yoshida, W. Y., Moore, R. E., and Paul, V. J. 2002. New apratoxins of marine cyanobacterial origin from Guam and Palau. Bioorg. Med. Chem. 10: 1973-1978.

Martins, J. C., and Vasconcelos, V. M. 2009. Microcystin dynamics in aquatic organisms. $J$. Toxicol. Environ. Health B 12: 65-82.

Martins, R., Fernandez, N., Beiras, R., and Vasconelos, V. 2007. Toxicity assessment of crude and partially purified extracts of marine Synechocystis and Synechococcus cyanobacterial strains in marine invertebrates. Toxicon 50: 791-799.

Martins, R., Pereira, P., Welker, M., Fastner, J., and Vasconelos, V. M. 2005. Toxicity of culturable cyanobacteria strains isolated from the Portuguese coast. Toxicon 46: 454-464.

Martins, R., Ramos, M., Herfindal, L., Sousa, J., Skaerven, K., and Vasconcelos, V.2008. Antimicrobial and cytotoxic assessment of marine cyanobacteria Synechocystis and Synechococcus. Mar. Drugs 6: 1-12.

Neilan, B., Jacobs, D., and Blackall, L. 1997. Rrna sequences and evolutionary relationships among toxic and nontoxic cyanobacteria of the genus Microcystis. Int. J. Syst. Bacteriol. 47: 693697. 
Nunnery, J. K., Mevers, E., and Gerwick, W. H. 2010. Biologically active secondary metabolites from marine cyanobacteria. Curr. Opin. Biotechnol. 21: 787-793.

Rippka, R., and Bazire, G. C. 1983. The cyanobacteriales: A legitimate order based on the type strain Cyanobacterium stanieri? Ann. Microbiol. 134B: 21-36.

Robertson, B. R., Tezuka, N., and Watanabe, M. M. 2001. Phylogenetic analyses of Synechococcus strains (cyanobacteria) using sequences of 16s Rdna and part of the phycocyanin operon reveal multiple evolutionary lines and reflect phycobilin content. Int. J. Syst. Evol. Microbiol. 51: 861-871.

Sambrook, J., and Russell, D. W. 2001. Molecular cloning: A laboratory manual, $3^{\text {rd }}$ ed. Cold Spring Harbor, NY: Cold Spring Harbor Laboratory Press.

Scanlan, D. J., Ostrowski, M., Mazard, S., Dufresne, A., Garczarek, L., Hess, W. R., Post, A. F., Hagemann, M., Paulsen, I., and Partensky, F. 2009. Ecological genomics of marine picocyanobacteria. Microbiol. Mol. Biol. Rev. 73: 249-299.

Schmidt, H. A., Strimmer, K., Vingron, M., and Haeseler, A. V. 2002. Tree-puzzle: Maximum likelihood phylogenetic analysis using quartets and parallel computing. Bioinformatics 18: 502504.

Semary, N., and Naby, M. 2010. Characterization of a Synechocystis sp. from Egypt with the potential of bioactive compounds production. World Microbiol. Biotechnol. 26: 1125-1133.

Stover, B. C., and Muller, K. F. 2010. Treegraph 2: Combining and visualizing evidence from different phylogenetic analyses. BMC Bioinformatics 11: 7.

Tamura, K., Peterson, D., Peterson, N., Stecher, G., Nei, M., and Kumar, S. 2011. Mega5: Molecular evolutionary genetics analysis using maximum likelihood, evolutionary distance, and maximum parsimony methods. Mol. Biol. Evolut. 28: 2731-2739.Tan, L. T. 2007. Bioactive natural products from marine cyanobacteria for drug discovery. Phytochemistry 68: 954-979.

Tan, L. T. 2010. Filamentous tropical marine cyanobacteria: A rich source of natural products for anticancer drug discovery. Appl. Phycol. 22: 659-676.

Waterbury, J. B., Watson, S.W., Valois, W., and Franks, D. G. 1986. Biological and ecological characterization of the marine unicellular cyanobacterium Synechococcus. Can. Bull. Fish. Aquat. 214: $71-120$.

Wright, E. S., Yilmaz, L. S., and Noguera, D. R. 2012. Decipher, a search-based approach to chimera identification for 16s rRNA sequences. Appl. Environ. Microbiol. 78: 717-725.

Zurawell, R. W., Chen, H., Burke, J. M., and Prepas, E. E. 2005. Hepatotoxic cyanobacteria: A review of the biological importance of microcystins in freshwater environments. J. Toxicol. Environ. Health. B 8: 1-37. 